\title{
Richard Francis Burton, os sambaquis e a Arqueologia no Brasil Imperial (Com tradução de textos de Burton)
}

\author{
Lúcio Menezes Ferreira* \\ Francisco Silva Noelli**
}

FERREIRA, L.M.; NOELLI, F.S. Richard Francis Burton, os sambaquis e a Arqueologia no Brasil Imperial. (Com tradução de textos de Burton). Revista do Museu de Arqueologia e Etnologia, São Paulo, 17: 149-168, 2007.

Resumo: $O$ principal objetivo deste artigo é apresentar a contribuição arqueológica de Richard Francis Burton no contexto brasileiro. Em seguida, apresentamos traduções de textos arqueológicos de Burton, os quais são de difícil acesso e ainda inéditos em português.

Palavras-chave: Arqueologia Pré-Histórica - Arqueologia Brasileira - Sambaquis.

institucionalização científica da Arqueologia brasileira, especialmente no século XIX, ainda é pouco conhecida. Conhecêla pormenorizadamente seria uma tarefa hercúlea, pois são muitas as fontes e as instituições a serem compulsadas. Dentre elas, os vários museus e institutos históricos formados no Império e na Primeira República, ao lado de instituições situadas fora do Brasil. O volume do material a ser lido, mesmo que nos restrinjamos às publicações destes museus e institutos, demandaria, com efeito, a formação de uma linha de pesquisa com equipes e colaboradores. ${ }^{1}$ Até mesmo porque, para

$\left({ }^{*}\right)$ Pesquisador Associado do Núcleo de Estudos Estratégicos (Unicamp). Bolsa de Pós-doutorado (FAPESP) luciomenezes@uol.com.br

(**) Professor Aposentado da Universidade Estadual de Maringá/Programa Interdisciplinar de Estudos de Populações.ffnoelli@wnet.com.br

(1) Esta proposta de formação de uma linha de pesquisa em História da Arqueologia brasileira foi tratada na tese de doutorado de Ferreira (2007: descrever o processo de institucionalização da Arqueologia brasileira, necessário se faria, também, considerar os documentos primários depositados nos arquivos dos museus e institutos. Tais documentos são importantes porque lidam com eixos temáticos de investigação: a elaboração de catálogos, a permuta e intercâmbio de coleções, e os relatos de viagens científicas que registram a ocorrência de sítios arqueológicos, escavações e obtenções de materiais. Como disse Paula Findlen (1996), o colecionismo, os catálogos e as viagens são fundamentais para a compreensão dos processos de institucionalização de uma ciência.

24-26). A presença da Arqueologia em textos literários e na imprensa do Império e da Primeira República, que será apenas aludida a seguir, é discutida mais longamente na tese, com indicação das fontes. A tese apresenta, ainda, como a Arqueologia institucionalizou-se articulada aos processos de mundialização da ciência, ao nacionalismo e ao colonialismo. 
Ademais, se admitirmos, ao menos como hipótese de trabalho, que a Arqueologia brasileira concatenou-se aos processos de mundialização da ciência, seria preciso fazer um apanhado extremamente minucioso da bibliografia e dos materiais arqueológicos presentes em museus estrangeiros. ${ }^{2}$ Tal levantamento é imprescindivel para situar os diálogos e colaborações entre pesquisadores do Brasil e do mundo, bem como para aquilatar o número e o valor de coleções levadas, desde o século XIX, para museus estrangeiros. Há, ainda, outras fontes a serem analisadas: a imprensa e romances do período. Quanto à primeira, os pesquisadores divulgavam descobertas e interpretações, registravam a localização de sítios, além de solicitarem recursos para pesquisa e o envio de artefatos para os museus locais. Nos romances, notadamente os naturalistas, há inúmeras informações e discussões arqueológicas, e mesmo figurações metafóricas.

É igualmente importante, para germinar uma futura linha de pesquisa em História da Arqueologia brasileira, escrever biografias de pesquisadores nacionais e estrangeiros e traduzir, para o vernáculo, textos raros e de difícil acesso. Neste artigo, damos um pequeno passo nesse sentido. Nosso objetivo principal é situar os textos de Richard Francis Burton sobre os sambaquis brasileiros, publicados

(2) As atividades científicas sempre ocorrem em lugares institucionais e geográficos específicos, carregando consigo as marcas discerníveis destes lugares de produção (Shapin: 1995). Porém, uma destas marcas é afetada pelo que os historiadores latino-americanos da ciência conceituam como mundialização da ciência: a circulação mundial da cultura científica a partir do século XVIII. A cultura científica, ao "globalizar-se", não imprimiu às instituições de pesquisa locais uma transferência passiva de modelos, mas produziu um conjunto de representações historicamente situadas, de articulações com as tradições locais de pesquisa e de respostas para os problemas políticos, sociais e econômicos de determinados contextos (Lafuente y Ortega 1992; Polanco 1990; Figueirôa 1998; Saldaña 1993). Pensamos que o internacionalismo referido pelos historiadores da Arqueologia, que seria responsável, durante o século XIX, pelos vínculos mundiais que formularam teorias arqueológicas (Kaeser 2000, 2001, 2002) e as concepções políticas dos arqueólogos (Díaz-Andreu 2007), coadunase com o conceito de mundialização da ciência. entre 1866 e 1874. Em seguida, apresentamos, em adendo a este artigo, traduções dos textos arqueológicos de Burton.

Esses textos, alguns deles, na verdade, consistindo de notas ligeiras e informativas, permanecem completamente desconhecidos pela Arqueologia brasileira. Apenas suas menções aos sambaquis da baía da Guanabara e à arte rupestre do baixo rio São Francisco foram lembradas (Beltrão 1978; Sousa 1991; Lima 1999-2000). Dentre seus coetâneos que atuaram no Brasil, somente o engenheiro alemão radicado em São Paulo, Carlos Rath (1871: 291), referiu-se a ele, lamentando que o "grande capitão", a caminho de suas explorações de Minas Gerais e do rio São Francisco, passou "à vapor" (com pressa!) pelos sambaquis da baía Guanabara. Em parte, a raridade dos textos de Burton decorre, inclusive, do fato de que ele foi "esquecido" por seus próprios colegas do Anthropological Institute durante o último quartel do século XIX (Penzer 1921:76).

\section{Burton e a Arqueologia}

Richard Francis Burton (1821-1890) foi um personagem de múltiplos talentos no contexto colonial vitoriano. Às vésperas de vir para o Brasil, era considerado por um dos seus conterrâneos como o "maior explorador de todos os tempos" (Farewell Dinner 1865:169).

Desempenhou muitas funções nas instituições do império britânico: oficial militar de carreira, espião, explorador, diplomata, cavaleiro do império. Burton era o próprio protótipo do Império, símbolo do viajante explorador, sequioso pelas fronteiras, inquieto pelos lugares distantes. O viajante timorato e incansável, sempre descortinando as regiões desconhecidas pelo olhar europeu, como a África Central (Torcato 1996; Gebara 2006). O cientista destemido que, no início dos anos 1860, antes de David Livingstone, procurou pelas nascentes do Nilo (Dugard 2005). Porém, antes de tudo, Burton é conhecido por sua competência lingüística; poliglota versátil, falava 19 línguas e vários dialetos (Rice 1991:19). Traduziu, para o inglês, livros escritos original- 
mente em árabe, persa, sânscrito, latim, italiano, francês e português, como As Mil e Uma Noites, a obra completa de Camões, o Kama Sutra e os escritos de Catulo (Penzer 1921; Wright 1906, v. 2; Lovell 2000).

Seu enorme apetite pelo conhecimento e pela Antropologia, no "truest meaning of the word" (Penzer 1921: 74), levou-o a publicar uma vastíssima obra, composta de 50 livros, vários com dois ou mais volumes, e centenas de artigos, cartas e notas. Até mesmo seus diários de viagem, recheados de detalhes que servem a variados objetos de estudo, mostram quão versáteis eram os apetites de Burton. Revelam outros aspectos, mais jocosos e pitorescos, de seu caráter aventureiro: suas pródigas "incursões" sexuais pelos territórios africanos e asiáticos (Hyam 1990).

Menos conhecido, contudo, é seu papel na institucionalização da Antropologia e da Arqueologia. Em 1861, tornou-se sócio da Ethnological Society (Penzer 1921: 75). Ajudou a fundar, em janeiro de 1863, a Anthropological Society of London, da qual foi o primeiro presidente. Fundou também revistas especializadas: a Journal of the Anthropological Society e a Anthropological Review (Wright 1906, v. 1: 185). Em uma época em que a Antropologia começava a delinear seus objetos e métodos, a Anthropological Society tinha a Arqueologia em pauta. Depois que a Ethnological Society e Anthropological Society foram fundidas em 1871 para formar o Anthropological Institute of Great Britain and Ireland, ${ }^{3}$ Burton criou uma nova instituição: a London Anthropological Society e o periódico Anthropologia (essa sociedade teve vida curta).

Fontes diversas e o conjunto da obra de Burton evidenciam que ele sempre se interessou pela Arqueologia. Ao longo de sua vida, desde os anos de estudo em Oxford, na carreira militar, nas explorações e na diplomacia, conviveu com vários praticantes da Arqueologia. Aos 24 anos, quando era um jovem oficial em Karachi (1845), levou uma

(3) Em 1905, o nome da instituição mudou para Royal Anthropological Institute of Great Britain and Ireland, que existe até hoje (Stocking 1971). equipe a escavar um sítio que acreditava ser um acampamento de Alexandre da Macedônia (Lovell 2000: 69). Mas foi apenas na maturidade que publicou resultados sistemáticos no livro Etruscan Bologna (1876). Trata-se de um trabalho de 275 páginas fartamente ilustrado, que hoje seria facilmente considerado como interdisciplinar. É realmente espantosa a amplitude de suas abordagens neste contexto italiano: Arqueologia, Bioantropologia, História, Lingüística, Geologia e Arte.

Burton assistiu à efervescência de um tema que passou a freqüentar assiduamente a agenda de debates da época: a "antiguidade do homem". Tema que surgiu na esteira de dois grandes eventos das Ciências Humanas e Naturais. O primeiro é a publicação de Origin of Species em 1859, de Charles Darwin, que popularizou e sistematizou o argumento central do evolucionismo e da antiguidade humana (Mayr 1991; Bowler 1996). O segundo é de 1863, quando Charles Lyell, então o geólogo inglês mais influente, publicou The Antiquity of Man, a síntese que estabeleceu o campo de estudos da relação Homo sapiens e ambiente projetados no tempo passado. Para Lyell (1863: 1): "nenhum objeto ultimamente excitou mais a curiosidade e o interesse geral entre geólogos e o público que a questão da Antigüidade do Homem". Lyell tratou da coexistência entre humanos e mamíferos extintos, da descoberta de artefatos pré-históricos, das três idades de Thomsen, da importância dos sítios arqueológicos e dos estudos sobre a variação do nível do mar para definir cronologias (Lyell 1863: 9 12). Também destacou o artigo de John Lubbock, de 1861 (Lyell 1863: 12), cujo nome Danish shell-mounds, or kjökkenmödding, inspiraria em 1866 o título quase homônimo de um artigo de Burton. Além dessas publicações, que certamente foram lidas por Burton, ${ }^{4}$ Lyell e Lubbock foram seus colegas na Ethnological

(4) O volume 1, número 3, da Anthropological Review fundada por Burton, publicou um debate sobre o recémlançado Antiquity of Man. Este volume 1(3) também comentava as pesquisas de Lubbock (Crawfurd 1863: 404, 433-437). Lubbock (1865: 198, 565), por seu turno, citou Burton. 
Society e, desde 1871, no Anthropological Institute (Keith 1934: 50). Lubbock, em 1865, ano em que Burton veio para o Brasil, publicou o primeiro grande clássico da arqueologia, Prehistoric times, onde incluiu seu Artigo de 1861.

Como se sabe, ao lado da Arqueologia escandinava e das pesquisas de Boucher de Perthes, as obras de Darwin, Lyell e Lubbock, ao confirmarem a "antiguidade do homem", foram pilares do estatuto científico da Arqueologia préhistórica (Daniel 1950; Groenen 1994: 37-94; Stiebing 1993: 29-54; Trigger 1990: 87). Pode dizer-se que Burton, portanto, ao chegar ao Brasil, já era íntimo e partícipe do processo de institucionalização da disciplina. Seu interesse pelos sambaquis brasileiros ditou-se exatamente pelo potencial destes sítios para as pesquisas em Arqueologia pré-histórica. Ademais, seus artigos e notas sobre os sambaquis, conquanto não resultem de pesquisas sistemáticas, ligam-se, como veremos, às pesquisas arqueológicas do Brasil Imperial.

\section{Burton e a Arqueologia Brasileira}

Burton veio para o Brasil para ocupar o cargo de cônsul em Santos, no qual permaneceu por três anos (1865-1868). A nosso ver, o mais brilhante estudo sobre o legado diplomático, exploratório e cultural de Burton no Brasil é o do crítico literário Alfredo Cordiviola (2001). Para Cordiviola, a narrativa de viagem do diplomata inglês - intitulada Explorations of the Highlands of the Brazil (1869a, b) $)^{5}$ - tramase às linhas de uma tradição apologética cujos ecos ainda nos soam aos ouvidos: a de que o Brasil seria o país do futuro. Podemos parafra-

(5) Neste trabalho fazemos uso dos volumes das Explorations e das traduções brasileiras. Américo Jacobina Lacombe publicou a primeira em 1941, reeditada em 1983 (Burton: 1983). David Ricardo Jardim Júnior fez nova tradução, publicada em 1977 e reeditada em 2001 (Burton 1977a, 1977b, 2001). Nossas citações referir-se-ão ao original e às traduções. As Explorations, como se sabe, são as narrativas de viagem de Burton pelo Rio de Janeiro, Minas Gerais e pelo rio São Francisco. sear Cordiviola, dizendo que, para Burton, o Brasil seria igualmente o país do passado; ou, então, o país que, tendo diversos sambaquis em suas franjas marítima e fluviais, possuiria parte significativa do futuro da pesquisa em Arqueologia pré-histórica. Numa palavra, o Brasil, com os seus ricos arquivos sobre a "antiguidade do homem", detinha um grande manancial para fomentar o progresso e o futuro da Arqueologia pré-histórica.

As principais biografias sobre Burton, entretanto, ocultam e esclarecem pouco sobre suas atividades arqueológicas no Brasil. $\mathrm{Na}$ mais antiga, sua sobrinha Georgina Stisted (1897: 311) diz que "é difícil acreditar que nosso viajante permaneceu dezoito meses em Santos sem nenhuma grande aventura", praticamente ignorando suas viagens e publicações e resumindo suas atividades culturais a palestras proferidas para Pedro II e círculos sociais restritos. Sua esposa, Isabel Burton ${ }^{6}$ (1916: $258,260,271$ ), relata sucintamente que ele fez "várias expedições por sua própria conta", antes da viagem a Minas Gerais e ao Rio São Francisco, sublinhando as relações sociais com a corte no Rio de Janeiro e com personalidades de São Paulo e Santos.

Foi Thomas Wright, em 1906, o primeiro biógrafo a revelar o interesse de Burton pela "arqueologia e história local" do Brasil. Relatou que, em Santos, Burton "explorou enormes kitchen middens de indios aborigines; mas sua atração maior foi o sítio de um forte português, sinalizado por uma pilha de pedras, onde um artilheiro, um Hans Stade [sic], foi capturado por canibais..." (Wright 1906, v. 1: 196-197). No final do livro, no apêndice IV, há uma lista de artigos de Burton sobre Arqueologia em geral e, especificamente, sobre o Brasil (Wright 1906, v. 2: viii, $\mathrm{x}$ ). Na única biografia de Burton traduzida e publicada no Brasil, Edward Rice (1991: 397) praticamente repete Wright, declarando que em Santos ele "dedicou muito tempo a explorações arqueológicas. Escavou ruinas

(6) W.H. Wilkins (1916), que concluiu e publicou a biografia de Isabel Burton e editou as palestras de Burton, também omitiu as atividades arqueológicas no Brasil. 
seculares de aldeias indigenas abandonadas e ruinas de fortes portugueses cobertos de mato".

Burton é, pode-se dizê-lo, um dos pioneiros das pesquisas arqueológicas no Brasil. Eventualmente, foi lembrado, como já dissemos anteriormente, por uma curta nota de rodapé sobre os sambaquis no Rio de Janeiro, publicadas em 1869 nas Explorations. Ele escreveu: "Aconselha-se aos antropólogos visitarem a Ilha Comprida [do Governador], onde há ostreiras chamadas localmente de sambaquis, ricas em crânios de aborígines e machados de pedra" (Burton 1869a: 23; 2001: 54). Na mesma obra refere-se à ocorrência de grafismos rupestres, passagem também recordada pela Arqueologia brasileira contemporânea, deduzindo que eles seriam comuns no baixo Rio São Francisco: "Tive o cuidado, contudo, de coligir para os futuros viajantes, as narrações ouvidas sobre os acidentes naturais de interesse, as reservas geológicas e as inscrições lapidares até hoje não estudadas". Além disso, Burton (1869b: 425, 1983: 57) prometeu publicar um livro para "mostrar claros vestigios de um povo esquecido, possuidor da terra anteriormente aos atuais selvagens (da raça tupi) e do qual nem a mais vaga tradição se conservou". Infelizmente, não cumpriu a promessa. Mas deixou um manuscrito intitulado The Eastern Coast of South America, datado de 1865, que merece ser avaliado para verificar se possui conteúdos de Arqueologia (Edwards H. Metcalf manuscript collection, Huntington Library, California). No livro Cartas do Paraguai, Burton (1870: 33) anunciou em nota que estava preparando um livro que se chamaria The lowlands of the Brazil, que possivelmente versaria sobre temas arqueológicos.

A produção de Burton sobre Arqueologia brasileira é mais extensa do que estas notas escritas nas Explorations. Chegando a Santos no dia 10 de novembro de 1865 (Burton 1874a: ii), ele logo foi explorar a região. Já no dia 11 de dezembro de 1865 , remeteu uma caixa com artefatos arqueológicos extraídos de sambaquis e escreveu uma carta para o presidente da Anthropological Society, denominada On a kjökkenmödding at Santos, Brazil, na qual narrou suas descobertas arqueológicas. Ela foi lida, em 15 de maio de 1866, no "Encontro da Socieda- de Antropológica" (Miscellanea Anthropologica: 1866: 208), e publicada pouco depois no quarto volume da Journal of the Anthropological Society of London (Burton 1866). Além desta carta, Burton publicou um artigo específico sobre sambaquis no primeiro volume da revista Anthropologica (Burton 1873). Há, ainda, um importante parágrafo em um artigo de 1871, que ele dedicou aos artefatos arqueológicos da "Terra Santa", onde ele informa sobre a distribuição geográfica dos sambaquis ao sul do Rio de Janeiro (Burton 1871). Também publicou o prefácio, a introdução e várias notas explicativas de sólida erudição etnológica e histórica sobre o Brasil, na tradução inglesa do livro de Hans Staden (Burton 1874a, 1874b). Logo no início do prefácio, relatou que visitou e explorou várias vezes os "kitchen middens" no litoral paulista (Burton 1874a: i).

Embora ele não tenha explicitado, certamente aportou no Brasil sabendo da existência de sambaquis. Leu sobre o assunto no capítulo Mounds of Santos in Brazil, ${ }^{7}$ do livro The Antiquity of Man, onde Lyell (1863: 42) analisou os dados publicados, em 1828, por Meigs nas Transactions of Philosophical Society. Acresce que, antes de Burton vir para o Brasil, Charles Carter Blake já havia publicado, na Anthropological Society, um artigo sobre fósseis humanos em cavernas do Brasil (Blake 1864). Burton conhecia também, como ele mesmo mostra nas Explorations, os trabalhos do dinamarquês Peter W. Lund, que nos anos 1830, ao pesquisar cavernas em Lagoa Santa (MG), descobriu fósseis humanos geologicamente associados com ossadas de megafauna. E Lund reportou a existência de sambaquis. Em 1844, ele escreveu uma carta sobre suas descobertas para a Sociedade Real dos Antiquários do Norte, fazendo analogias arqueológicas e etnográficas entre os sambaquis do Brasil e os da Dinamarca (Lund 1950 [1844]: 467).

(7) No sumário do capítulo 3 Lyell (1863: v, 33), cita como Sepulchral Mound of Santos in Brazil. 
Em suma, Burton, ao vir para o Brasil, ciente que estava do processo de institucionalização da Arqueologia pré-histórica, da gestação dos debates evolucionistas e acerca da "antiguidade do homem", procurou por sambaquis. O reclame de Rath (1871: 291) sobre a vista de soslaio e apressada de Burton sobre os sambaquis da baía de Guanabara não se sustenta porque, como veremos nas traduções a seguir, o inglês reitera que sua intenção era dar notícia ao invés de fazer pesquisa, dizendo que: eu mal posso encontrar tempo no presente para trabalhar sobre minhas extensas notas sobre este tema; mas serei o mais feliz em colocá-los nas mãos de membros irmãos que tiverem mais tempo e a inclinação para tentar a tarefa (Burton 1871: 300).

Sua estada no Brasil, durante a qual estreitou contatos com os cientistas e autoridades locais, pode ter-lhe proporcionado informações mais exatas sobre a distribuição geográfica e os conteúdos arqueológicos dos sambaquis. Sobre tais contatos, não temos ainda dados precisos. Mas podemos avançar algumas considerações, que talvez abram veredas para futuras pesquisas. Tanto D. Pedro II, patrono do Instituto Histórico e Geográfico Brasileiro (IHGB) e notório colecionador de cultura material arqueológica e etnográfica, como outros personagens do Império, provavelmente forneceram-lhe informações arqueológicas que auxiliaram suas investigações. Com Pedro II seus encontros não foram apenas protocolares, mas sociais e intelectuais, como ele próprio e sua esposa Isabel comentam. Burton, por volta de junho de 1866, proferiu para Pedro II palestras sobre suas viagens a Medina, Meca, Harar, ao "Coração da África” e aos Estados Unidos, que postumamente foram reunidas e publicadas no livro Wanderings in Three Continents (Burton 1901; Wilkins 1901).

Burton menciona que, durante suas estadas no Rio de Janeiro, conversou com Ladislau de Souza Mello Neto (cf. Burton 1874b: lxxx), que viria a ocupar, entre 1874 e 1893, a direção do Museu Nacional. Trata-se de um contato importante, pois Ladislau Neto conhecia bem os sambaquis. Neto promoveu pesquisas sobre estes sítios no Museu Nacio- nal, ele mesmo os escavou no Sul do Brasil e deixou-nos publicações sobre o tema (Neto 1882, 1885: 263-275).

Além dos contatos de Burton, que necessitam de maiores e mais extensas pesquisas ulteriores, uma importante fonte literária deve ser cotejada. Trata-se do IHGB. É verdade que Burton queixou-se acidamente por não ter sido convidado para participar das reuniões semanais do IHGB (Burton 1869a:15), onde a pesquisa arqueológica vicejou desde a criação da instituição, em 1838 (Ferreira 1999, 2003). Entretanto, as Explorations mostram que Burton leu atentamente a Revista do Instituto, para aprofundar seus conhecimentos sobre História e Geografia do Brasil e amealhar dados para sua viagem pelo rio São Francisco. Decerto Burton, como ele mesmo nos conta nas Explorations, valeu-se de uma série de narrativas de viagens de naturalistas que percorreram o Brasil antes dele; mas a Revista do IHGB não pode ser desprezada como fonte privilegiada de Burton. $\mathrm{O}$ explorador leu-a, como vemos nas Explorations, na Faculdade de Direito de São Paulo, instituição que ele freqüentava regularmente e onde havia uma coleção da Revista.

Na Revista do IHGB ele certamente deparou com várias análises sobre sambaquis e Arqueologia brasileira em geral. Conquanto não as cite diretamente, podemos supor que atentou ao menos para algumas das discussões estampadas na Revista. Em primeiro lugar, nos primeiros volumes da Revista estão publicadas as cartas de Lund, nas quais o naturalista dinamarquês argumenta pela coexistência do "homem de Lagoa Santa" com a megafauna extinta (Lund 1842, 1844). Em segundo lugar, no final dos anos 1840 e início dos anos 1850 , os sambaquis estavam em pauta no IHGB. Um dos membros do Instituto que trouxe à tona discussões sobre os sambaquis foi o historiador Francisco Adolfo Varnhagen, o autor da História Geral do Brasil (1975 [1854]). Nesta obra magna de Varnhagen, a arqueologia e a etnografia figuram com destaque (Ferreira 2005a). Burton cita a História Geral do Brasil nas Explorations, portanto, obviamente lidou com as pesquisas Arqueológicas e Etnográficas do Visconde de Porto Seguro. 
Varnhagen discorrera sobre os sambaquis antes de publicar a História Geral do Brasil. Em Etnografia Indígena: Linguas, Imigrações e Arqueologia (1849), Varnhagen, propondo a efetivação de uma seção especializada em Etnografia e Arqueologia no Instituto, comentou os "últimos achados arqueológicos" em território brasileiro: machados líticos, igaçabas, vestígios cerâmicos e outros (Varnhagen 1849: 370). Varnhagen descreveu também um sambaqui maranhense, classificando-o como "mausoléu" (Varnhagen 1849: 372). Tal descrição levou o eminente naturalista Francisco Freire Alemão a escrever uma memória - Memória sobre a Pirâmide do Campo Ourique do Maranhão (RIHGB, tomo $12,521,1850)$-, que infelizmente permanece inédita.

Provavelmente, Burton considerou estas e outras informações na Revista do IHGB. De todo modo, as fontes literárias e os contatos pessoais de Burton requerem, no-lo reiteramos novamente, melhor garimpagem e exame nos arquivos do Brasil e da Inglaterra. Contudo, mesmo que ainda não tenhamos mapeado circunstancialmente as relações sociais e intelectuais de Burton, já podemos afirmar que sua contribuição às pesquisas arqueológicas brasileiras é extremamente valiosa. Burton não fez escavações minuciosas, mas coletou amostras dos sambaquis. Advertiu, num tom modesto e comedido, que faria apenas divulgação dos sambaquis brasileiros; seu objetivo principal era granjear coleções de artefatos e esqueletos. Pelo que depreendemos de seus textos, Burton formou duas coleções. Uma delas doou à Anthropological Society. A outra consistiu de uma coleção particular. Ele vendeu uma pequena parte desta coleção (veja a tradução mais abaixo) e, em 1884, doou-a a August Pitt Rivers (Petch 2006; sobre as doações ver http://history.prm.ox.ac.uk), quando o General arqueólogo preparava-se para retirar seus 14.000 artefatos do British Museum of Natural History e transferi-los para o recém-fundado Museu da Universidade de Oxford (Bowden 1999). O Museu de Oxford, que hoje, como sabemos, se chama Pitt Rivers Museum, ainda possui a coleção brasileira doada por Burton.
Certamente, como o olhar especializado do leitor arqueólogo observará nas traduções que oferecemos, as interpretações de Burton sobre os sambaquis possuem erros e incongruências. Contudo, a contribuição do cientista inglês é inegável. Podemos sumarizála do seguinte modo: 1) constatou a ocorrência de 20 sambaquis na costa de Santos; 2) constatou a ocorrência de sambaquis em Ubatuba; 3) constatou a ocorrência de sambaquis na área de Cananéia; 4) constatou que ocorriam sambaquis na costa do Paraná, Santa Catarina e Rio Grande do Sul; 5) aventou a hipótese, a partir da amostragem amealhada entre o Rio de Janeiro e o Rio Grande do Sul, de que existiriam sambaquis do Oiapoque ao Rio da Prata; 6) deduziu que os sambaquis eram pré-históricos; 7) realizou descrições da estratigrafia e do contexto arqueológico dos sambaquis; 8) coletou amostras, escavando-as e recebendo doações; 9) verificou que havia um padrão de inserção dos sambaquis na paisagem, especialmente associados com os cursos de água potável e os mangues, onde havia fontes alimentícias; 10) sugeriu hipóteses sobre a construção e a ocupação social dos sambaquis. Atento ao avanço das pesquisas sobre a relação entre os sambaquis europeus e a regressão/transgressão marinha, Burton advertiu em 1873 sobre a inconsistência da interpretação popular e científica da origem dos sambaquis brasileiros: O ignorante não consegue acreditar que esses montes resultaram de trabalho manual do homem, atribuindo-o ao dilúvio de Noé, ou a algum outro suposto distúrbio. Homens instruidos têm igualmente defendido esse absurdo em publicações (veja tradução abaixo). Burton não imaginava que essa interpretação teria vida longa na Arqueologia brasileira.

Um fato interessante, comum ao conjunto da obra de Burton, é a constante menção que $\mathrm{faz}$ dos seus interlocutores em campo, referindo-se às suas informações práticas e analisando suas ponderações e interpretações de interesse arqueológico.

Estas interpretações de Burton podem e devem ser historicamente articuladas às pesquisas arqueológicas do Brasil Imperial. 
Elas se imbricam em uma série de outros trabalhos, feitos por cientistas estrangeiros e brasileiros. Dentre os primeiros, em 1864, antes da chegada de Burton ao Brasil, o francês Conde de La Hure escavou sambaquis de Santa Catarina. Escreveu um competente relatório sobre suas escavações, enviando-o para o IHGB (La Hure 1865); o relatório, infelizmente, permanece inédito, esperando por tradutores e publicação. Por sua vez, o diplomata e cientista Charles Wiener, comissionado para o Museu Nacional por Ladislau Neto (1876), retornou, em 1876, a Santa Catarina, produzindo um importante estudo sobre os sambaquis fluviais e marítimos da região (Wiener 1876). No final dos anos 1870 e início dos anos 1880 , cientistas alemães, a exemplo de Karl von den Steinen, remeteram os materiais de sambaquis de São Paulo (Santo Amaro) e Santa Catarina (São Francisco do Sul e Joinvile) para o Museu de Berlim; tais materiais permitiram ao fundador e diretor da instituição, o famoso antropólogo Rudolf Virchow, escrever três importantes trabalhos (Faria 2003).

Outros cientistas estrangeiros se somariam a esta pequena lista. Mas o fato é que eles e o próprio Burton não escreveram em hiato empírico e interpretativo. Já havia, no Brasil, uma tradição local de pesquisa, como enunciamos brevemente acima, a propósito do IHGB. Os cientistas estrangeiros dialogaram ativamente com esta tradição local, e vice-versa, dando vazão aos fluxos do processo de mundialização da ciência (Ferreira 2007). A partir dos anos 1870 , com a consolidação das teorias evolucionistas no Brasil, intensificaram-se as escavações sobre os sambaquis (Ferreira 2005b). Na revista Ensaios de Ciência, assim, surgiram pesquisas sobre os sambaquis de Santos e da Amazônia, feitas, respectivamente, por Gustavo Such Capanema (1876) e João Barbosa Rodrigues (1876). Pelo Museu Nacional, além dos trabalhos de Ladislau Neto, o naturalista viajante da instituição, Domingos Soares Ferreira Pena, escavou os sambaquis do Pará (Pena 1876); e João
Batista Lacerda, futuro diretor da instituição, dissertou, sob o ponto de vista da Antropologia Física, sobre o "homem" do sambaqui (Lacerda 1885).

Para não estendermos mais a lista de publicações, finalizamos concluindo que estas pesquisas, feitas por brasileiros e estrangeiros, pretendiam o mesmo que Burton: constituir a Arqueologia pré-histórica como disciplina científica e reunir empirias para o debate sobre a "antiguidade do homem". De todo modo, será preciso que, no futuro, contemos com outros estudos mais detalhados e balizados do que o nosso, tenham eles como objeto Burton ou qualquer outro cientista brasileiro ou estrangeiro. Somente assim comporemos novos elementos comparativos para organizarmos uma linha de pesquisa em História da Arqueologia brasileira, devidamente inserida no campo de História da Ciência.

\section{As Traduções}

Procuramos manter o tom original dos textos, marcados pela linguagem coloquial, pelas inevitáveis figuras de linguagem e pelas abruptas oscilações temáticas. Nossa idéia foi manter o sabor e a tonalidade da narrativa de Burton. Atualizamos a toponímia e a nomenclatura dos componentes do relevo, mas não alteramos as medidas.

Esta série de publicações, realizadas entre 1866 e 1874 , constitui-se de:

1) Uma carta de dezembro de 1865 , publicada em 1866;

2) Uma nota de rodapé, em 1869 , no primerio volume das Explorations;

3) Um parágrafo de um artigo sobre a Terra Santa, em 1871;

4) Um artigo específico sobre os sambaquis, em 1873;

5) Fragmentos do prefácio à edição inglesa do livro de Hans Staden, em 1874 (devido a sua extensão serão publicados posteriormente). 


\section{Agradecimentos}

Alfredo Cordiviola gentilmente nos enviou cópia do artigo de 1873 , publicado na rara revista Anthropologia. Amílcar D’Ávila de Mello revisou nossa tradução, melhorando a qualidade do texto e ajudando a manter o sabor da versão inglesa. Maria Isabel D’Agostino Fleming deu valiosas sugestões para corrigir e melhorar o artigo. Contudo, a responsabilidade é restrita aos autores.

FERREIRA, L.M.; NOELLI, F.S. Richard Francis Burton, the shell mounds and Archaeology in Imperial Brazil. (With translation of Burton's texts). Revista do Museu de Arqueologia e Etnologia, São Paulo, 17: 149-168, 2007.

Abstract: The main aim of this paper is to raise some matters about the Brazilian context of the archaeological productions of Richard Francis Burton. We offer translations of the archaeological texts of Richard Francis Burton as well, which are hard to find and still unavailable in Portuguese.

Keywords: Prehistoric Archaeology - Brazilian Archaeology - Shell mounds.

\section{Referências bibliográficas}

BELTRÃO, M.C.

1978 Pré-História do Estado do Rio de Janeiro. Rio de Janeiro: Forense/SEEC-RJ.

BLAKE, C.C.

1864 On Human Remains from a Bone Cave in Brazil. Anthropological Society, 2: 10-31.

BOWDEN, M.

1999 August Pitt Rivers. In: Murray, T. (Ed.) Encyclopedia of Archaeology: The Great Archaeologists. Oxford: ABC-CLIO: 127-140.

BOWLER, P.J.

1996 Charles Darwin: the man and its influence. Cambridge: Cambridge University Press.

BURTON, I. (ISABEL)

1893 (ver abaixo WILKINS, W. H. 1916)

BURTON, R.F.

1866 Letter on a kjökkenmödding at Santos, Brazil. Journal of the Anthropological Society of London, 4: cxcii-cxciv.

1869a/ Explorations of the Highlands of the Brazil, with a full account of the gold and diamond

$1869 \mathrm{~b}$ mines. Also, canoeing down 1500 miles of the great river São Francisco from Sabará to the Sea. London: Tinsley Brothers. 2v.

1870 Letters from the Battlefields of Paraguay. London: Tinsley Brothers.
1871 On Anthropological Collections from the Holy Land, with notes on the Human Remains by Dr C. Carter-Blake. Journal of the Anthropological Institute, 1: 300-312.

1873 Notes on the Kitchen-Middens of Sao Paulo, Brazil, and the Footprints of St Thomas, Alias Zome. Anthropologia, 1: 44-59.

1874a Preface. In: The captivity of Hans Stade of Hesse. London: Hakluyt Society: i-lvii.

1874b Introduction. In: The captivity of Hans Stade of Hesse. London: Hakluyt Society: lxi-xciv.

1876 Etruscan Bologna. A study. London: Smith, Elder \& Co.

1901 Wanderings in three continents. London: Hutchinson \& Co.

1941 Viagem aos Planaltos do Brasil. Tradução de Américo Jacobina Lacombe. São Paulo: Cia. Editora Nacional. 3 v.

1977a Viagem do Rio de Janeiro ao Morro Velho. Tradução David Ricardo Jardim Júnior. Belo Horizonte/São Paulo: Itatiaia/ EDUSP.

1977b Viagem de Sabará ao Oceano Atlântico. Tradução David Ricardo Jardim Júnior. 
Belo Horizonte/São Paulo: Itatiaia/ EDUSP.

2001 Viagens do Rio de Janeiro ao Morro Velho. Tradução David Ricardo Jardim Júnior. Brasília: Senado Federal.

CAPANEMA, G. S.

1876 Os Sambaquis. Ensaios de Ciência, 1: 81-89.

CORDIVIOLA, A.

2001 Richard Burton, a traveller in Brazil. 1865. 1868. New York: Edwin Mellen Press.

CRAWFURD, J.

1863 Notes on Sir C. Lyell's "Antiquity of Man". Anthropological Review, 1 (3): 433-437.

DANIEL, G.

1950 A Hundred Years of Archaeology. London: Duckworth.

DARWIN, C.

s/d The Origin of Species. London, New York:

[1859] The Modern Library.

DÍAZ-ANDREU, $\mathrm{M}$.

2007 Internationalism in the Invisible College: Political Ideologies and Friendships in Archaeology. Journal of Social Archaeology, 7 (1): 29-48.

DUGARD, $\mathrm{M}$.

2005 No Coração da África: As Aventuras Épicas de Livingstone e Stanley. Rio de Janeiro: Record.

FAREWELL DINNER TO CAPTAIN BURTON

1865 Anthropological Review, 3 (9): 167-182.

FARIA, L. de C.

2003 Virchow e os Sambaquis Brasileiros. In: Domingues, H.M.B; SÁ, M.R; GLICK, T. (Orgs.) A Recepção do Darwinismo no Brasil. Rio de Janeiro, Editora Fiocruz: 125-144.

FERREIRA, L.M.

1999 Vestígios de Civilização: O Instituto Histórico e Geográfico Brasileiro e a Construção da Arqueologia Imperial (1838-1870). Revista de História Regional, 4 (1): 9-36.

2003 História Petrificada: A Arqueologia Nobiliárquica e o Império Brasileiro. Cadernos do CEOM, 17/18: 11-40.

2005a Footsteps of American Race: Archaeology, Ethnography and Romanticism in Imperial Brazil. In: Funari, P.P.A.; Zarankin, A.; Stovel, E. (Eds.) Global Archaeology Theory: Contextual Voices and Contemporary Thoughts. New York, Kluwer Academic: 337-352.

2005b Solo Civilizado, Chão Antropofágico: A Arqueologia Imperial e os Sambaquis.
In: Funari, P.P.A.; Orser Jr., C.; Schiavetto, S.N. de O. (Orgs.) Identidades, Discurso e Poder: Estudos da Arqueologia Contemporânea. São Paulo, Annablume/FAPESP: 135-146.

2007 Território Primitivo: A Institucionalização da Arqueologia no Brasil. Campinas: Instituto de Filosofia e Ciências Humanas, Unicamp: Tese de Doutorado.

FIGUEIRÔA, S.F.M. de

1998 Mundialização da Ciência e Respostas Locais: sobre a institucionalização das ciências naturais no Brasil (de fins do século XVIII à transição do século XX). Asclépio, 50 (2): 107-123.

FINDLEN, P.

1996 Possessing Nature: Museums, Collecting, and Scientific Culture in Early modern Italy. Berkley: University of California Press.

GEBARA, A.L.A.

2006 O discurso de Richard Francis Burton sobre a África Ocidental: uma análise da construção de suas representações. São Paulo: Tese de Doutorado FFLCH-USP.

GROENEN, M.

1994 Pour une Histoire de la Préhistoire. Grenoble: Éditions Jérome Millon.

HYAM, R.

1990 Empire and Sexuality: the British Experience. Manchester: Manchester University Press.

KAESER, M.A.

2000 Nationalisme et Archéologie: quelle histoire? Rerue d'Histoire des Sciences Humaines, 2: 155-162.

2001 L'internationalisation de la Préhistoire, une manouevre tactique? Les conséquences épistémologiques de la fondation des congrés internationaux d'anthropologie et d' archéologie préhistoriques. In: Blanckaert, C. (Ed.) Les Politiques de l'antropologie: Discours et Práctiques en France (1860-1940) (Histoire des Sciences Humaines). Paris, L'Harmattan : 201-230.

2002 On the International Roots of Prehistory. Antiquity (Special Section: Ancestral Archives, Explorations in the History of Archaeology), 76: 170-177.

KEITH, A.

1934 Centenary of the Birth of Lord Avebury. Man, 34: 49-51.

LA HURE, CONDE de

1865 Consideratións Summaires sur L’Origine des Amas de Coquillages de la Côte du Brésil. Dona Francisca (SC), 10.02.1865. IHGB, lata 15, pasta 9 (manuscrito). 
LACERDA, J.B.

1885 O Homem dos Sambaquis (Contribuição para a Antropologia Brasileira). Arquivos do Museu Nacional, 6: 175-203.

LAFUENTE, A.; ORTEGA, M.L.

1992 Modelos de Mundilización de la Ciencia. Madrid, Arbor, Tomo CXLII: 93-117.

LIMA, T.A.

1999-2000 Em busca dos frutos do mar: os pescadores-coletores do litoral centro-sul do Brasil. Revista USP, 44 (2): 270-327.

LOVELL, M.S.

2000 A rage to live: a biography of Richard and Isabel Burton. New York: W.W. Norton $\&$ Comp.

LUBBOCK, J.

1865 Prehistoric times, as illustrated by ancient remains, and the manners and customs of modern savages. s.l.: Williams \& Norgate.

LUND, P.W.

1842 Carta Escrita de Lagoa Santa (MG), ao Sr. Primeiro Secretário do Instituto, pelo sócio honorário Dr. Lund. RIHGB, 4: 80-87.

1844 Carta do Dr. Lund, escrita de Lagoa Santa (MG) a 21 de abril de 1844 . RIHGB, 6: 334-342.

1950 Notícia sobre as ossadas fósseis achadas

[1844] numa caverna do Brasil. In: Memórias sobre a Paleontologia Brasileira. Rio de Janeiro: Instituto Nacional do Livro: 465-468.

LYELL, C.

1863 The Antiquity of Man: with remarks on theories of the Origins of Species by variation. London: John Murray.

MAYR, E.

1991 One Long Argument: Charles Darwin and the Genesis of Modern Evolutionary Thought. Cambridge: Harvard University Press.

MISCELLANEA ANTHROPOLOGICA. ANTHROPOLOGICAL SOCIETY'S MEETINGS.

1866 Anthropological Review, 4 (13): 208.

NETO, L. DE S.M.

1876 Carta a Charles Wiener. Arquivos do Museu Nacional, 1: 1-2.

1882 A Origem dos Sambaquis. Revista da Exposição Antropológica Brasileira. Rio de Janeiro: Tipografia Pinheiro: 37-38.

1885 Investigações sobre a Arqueologia brasileira. Arquivos do Museu Nacional, 6: 257-553.

PENA, D.S.F.

1876 Breve Notícia sobre os Sambaquis do Pará. Arquivos do Museu Nacional, 1: 85-99.
PENZER, N.

1921 Sir Richard Francis Burton. Man, 21: 74-76. PETCH, A.

2006 Chance and certitude. Pitt Rivers and his first collection. Journal of the History of Collections, 18 (2): 257-266.

PITT-RIVERS MUSEUM

http://history.prm.ox.ac.uk (consultado em 20/07/2007).

POLANCO, $\mathrm{X}$.

1990 Une Science-monde: la mondialisation de la science européenne et la création de traditions scientifiques locales. In: Polanco, X. (Ed.) Naissance et Développement de la Science-Monde: production and reproduction des communautés scientifiques en Europe et en Amérique Latine. Paris, Ed. La Découverte/ Conseil de l'Europe/UNESCO: 5-15.

RATH, C.

1871 Notícia etnológica sobre um povo que já habitou a costa do Brasil, bem como seu interior, antes do dilúvio universal. Revista Trimensal do Instituto Histórico, Geográfico e Etnográfico do Brasil, 34 (1): 287-292.

RICE, E.

1991 Sir Richard Francis Burton. O agente secreto que fez a peregrinação à Meca, descobriu o Kama Sutra e trouxe as Mil e Uma Noites para o Ocidente. São Paulo: Cia das Letras.

RODRIGUES, J.B.

1876 Antigüidades do Amazonas. Ensaios de Ciência. Rio de Janeiro, Brown e Evaristo, 1: 93-125.

SALDAÑA, J.J.

1993 Nuevas tendencias en la Historia de la ciencia en América Latina. Cuadernos Americanos, 38 (2): 69-91.

SHAPIN, S.

1995 Here and Everywhere: Sociology of Scientific Knowledge. Annual Review of Sociology, 21: 289-321.

SOUSA, A.M.

1991 História da Arqueologia Brasileira. Pesquisas, Antropologia, 46.

STADEN, H.

1874 The Captivity of Hans Stade of Hesse, in A.D. 1547-1555, Among the Wild Tribes of Eastern Brazil. Translated by Albert Tootal and annotated by Richard F. Burton. London: Hakluyt Society.

STIEBING, W.H. JR.

1993 Uncovering the Past: A History of Archaeology. Oxford: Oxford U. P. 
STISTED, G.M.

1897 The true life of Capt. Sir Richard F. Burton. London: H. S. Nichols.

STOKING JR. G.W.

1971 What's in a Name? The Origins of the Royal Anthropological Institute (1837. 71). Man, new series, 6 (3): 369-390.

TORCATO, L.

1996 Sir Richard Francis Burton. Andarilho na fronteira. São Paulo: Dissertação Mestrado FFLCH-USP.

TRIGGER, B.G.

1990 A History of Archaeological Thought. Cambridge: Cambridge U.P.

VARNHAGEN, F.A.

1849 Etnografia Indígena: Línguas, Imigrações e Arqueologia. RIHGB, 11: 366-376.
1975 História Geral do Brasil. 9 ed. São Paulo:

[1854] Melhoramentos.

WIENER, C.

1876 Estudos sobre os Sambaquis do Sul do Brasil. Arquivos do Museu Nacional, 1: 3-20.

WILKINS, W.H.

1901 Preface. In: Richard F. Burton. Wanderings in three continents. London, Hutchinson $\&$ Co.: vii-xiii.

1916 The Romance of Isabel Lady Burton. The history of her life told in part by herself and in part by W. H. Wilkins. New York: Dodd Mead \& Company.

WRIGHT, T.

1906 The life of Sir Richard Burton. London/ New York: G. P. Putnam \& Sons/Everet \& Co. 2v.

\title{
Traduções de textos e artigos de Richard Francis Burton sobre Arqueologia no Brasil Império - (textos ordenados cronologicamente)
}

\author{
Sobre um Sambaqui em Santos, Brasil ${ }^{8}$
}

\author{
Richard Francis Burton
}

Consulado Britânico, Santos, Brasil, 11 de dezembro de 1865.

Sir, envio por este correio uma pequena caixa com implementos líticos, etc.,

recentemente encontrados por mim e outros em várias partes da baía de Santos. As cinqüenta léguas de costa de Angra dos Reis até o rio Cananéia foram habitadas pelos índios Guaianás, ${ }^{9}$ que divisavam acima ao norte com os Tamoio e ao sul com os Carijó.

Os índios Guaianás são uma tribo domesticada; eles preferem apenas escravizar a matar e comer seus prisioneiros, e são aparentados com os brancos. Por causa disso, Martim Afonso de Sousa achou fácil colonizar suas terras. Eles nunca guerreiam contra seus vizinhos fora de seus próprios limites, e lutam nos "Campos" abertos ou pradarias brasileiras, não na mata. Eles não têm nem plantações nem aldeias como os Tamoio; suas moradias são cavernas ou buracos no chão, onde mantêm o fogo aceso noite e dia, e suas camas são as peles dos animais selvagens que matam como alimento.

Isto soubemos através do Novo Orbe Seráfico Brazilico, ${ }^{10}$ do Frei Antônio de Santa Maria [Jaboatão], 1761.

(8) Título original: On a Kjökken-mödding at Santos, Brazil. Journal of the Anthropological Society of London, 4: cxciiicxciv. 1866. Tradução: Francisco Silva Noelli e Lúcio Menezes Ferreira. Revisão: Amílcar D’Avila de Mello.

(9) Burton confunde os Guaianá, que eram Jê, com os Tupiniquim, que eram Tupi e os autores da toponímia da costa.

(10) Provavelmente, Burton teve à sua disposição a edição do Instituto Histórico e Geográfico Brasileiro, Rio de Janeiro:

v. 1 (1859), v. 2 (1861), v. 3 (1862). 
Estes "negros", como o povo ainda costuma chamá-los, desapareceram dos arredores da baía de Santos logo depois de 1532, quando os portugueses fundaram São Vicente. Era seu costume seguir os animais selvagens nas suas migrações anuais das terras altas do interior durante o assim chamado inverno - maio a setembro - e vice-versa. À beira-mar eles parecem viver principalmente de ostras e outros mariscos. Eles devem ter terras determinadas para acampar, geralmente entre os manguezais, onde os caranguejos e outros tipos de crustáceos são comuns. Eles amontoam as conchas vazias em enormes montes, e neles enterram seus mortos. Aparentemente, os montes são freqüentemente duplos, separados por um pequeno córrego ou [curso de] água fresca, como se cada subtribo ou família tivesse seu traçado peculiar. Existem cerca de vinte destes kjökken-möddings na baía de Santos, além de muitos costa abaixo, em Iguape, Cananéia e suas praias marítimas para o sul. Alguns possuem grandes dimensões. Em 3 de dezembro, em companhia dos senhores João Batista da Silva Bueno, ${ }^{11}$ e dos senhores Glennie ${ }^{12}$ e Miller desta cidade, visitei um depósito na "Ilha do Casqueiro", a nordeste de Santos. Ela contém três montes, um deles tem cerca de 200 pés de altura e um perímetro de aproximadamente 2.800 pés. As ostras em questão (das quais envio um espécime) formam um conglomerado cujos blocos alcançam uma tonelada de peso. Eles têm abastecido o país de cal pelos últimos três séculos e continuarão a fazê-lo ainda por um longo tempo. Os números $1 \mathrm{e}$ 2 provêm de jazidas de olarias próximas de Santa Rita, ao norte da baía de Santos. Foram-me dados pelo senhor Antônio José da Silva Campella. Prometo outros espécimens se você desejar recebê-los, e farei o possível para conseguir alguns esqueletos dessa raça extinta para a Anthropological Society.

Sou, Sir, seu obediente servo, Richard Burton, Vice-Presidente da Anthropological Society.

O presidente declarou que a caixa contendo os exemplares referidos na carta ainda não chegou.

\section{Nota de advertência publicada no primeiro volume das Explorations of The Highlands of Brazil ${ }^{13}$}

Aconselha-se aos antropólogos visitarem a Ilha Comprida [do Governador], onde há ostreiras chamadas localmente de sambaquis, ricas em crânios de aborígines e machados de pedra.

(11) Juiz comercial da Comarca de Santos, conforme Francisco Martins dos Santos. História de Santos 1532-1936. São Paulo: Revista dos Tribunais, 1937.

(12) C.A. Glennie, cônsul em exercício em Santos, "há longo tempo", de acordo com Richard Burton, Explorations of The Highlands of Brazil. London: Tinsley Brothers, 1869a, p. 5, nota.

(13) Foi a única menção ao trabalho arqueológico de Burton citada pela bibliografia arqueológica brasileira: BURTON, R.F. [1869] Viagem do Rio de Janeiro a Morro Velho. Tradução de David Jardim Júnior. Brasília: Senado Federal, 2001: 54. 


\section{Parágrafo sobre a distribuição dos sambaquis na costa meridional do Brasil ${ }^{14}$}

Isto, talvez, não seja geralmente conhecido, inclusive nesta sala [da Anthropological Society], que a costa brasileira, do Rio de Janeiro à Província do Sul, Rio Grande do Sul, é franjada com uma poderosa linha de kitchen-middens. Eles são encontrados desde a baía do Rio [de Janeiro], sobre as praias da Ilha Grande [do Governador]; de minha agradável e saudável estação, Santos, uma Serra Leoa do Brasil, eu remeti para esta Sociedade exemplares de machados usados pela raça Tupi para abrir mariscos, na maior parte, da classe denominada paleolítica ou arcaica.

\section{$*$ \\ $* *$ \\ Notas sobre os sambaquis de São Paulo, Brasil ${ }^{15}$ \\ Richard F. Burton, capitão, F.R.G.S., ${ }^{16}$ V.P.L.A.S.}

Os imensos sambaquis da costa brasileira têm sido completamente ignorados pelos viajantes. Acredito ser o primeiro estrangeiro que chamou a atenção para esses depósitos pré-históricos e que enviou para casa alguns exemplares de implementos de pedra que estão contidos em todos eles.

Não é improvável que toda a costa, do Oiapoque e do Amazonas até o Prata, e além, seja pontilhada com montes de conchas que se erguem alinhados. Na baía do Rio de Janeiro tive notícia deles na Ilha Grande. A monografia do Frei Gaspar da Madre de Deus, Memórias para a história da Capitania de São Vicente, hoje Província de São Paulo, etc. (primeira publicação em 1747), informa que eles serviram de cal desde que o país foi descoberto, que não se estendem ao norte do braço de mar Bertioga (pelo contrário, eles existem sobre Ubatuba), mas se alastram abaixo de Cananéia, para a Província de Santa Catarina. Uma história local do sul da Província do Paraná, ${ }^{17}$ que infelizmente desapareceu da minha pequena coleção, dá uma longa e detalhada descrição deles e, de fato, a sua importância como os únicos depósitos de cal de uma região granítica provavelmente não os torna desprezíveis pelas autoridades nativas, que conhecem bem o país.

Os portugueses chamam-nos de ostreiras (banco de ostras). O nome indígena é sambagué ou sambaqui, que significa o mesmo. Na África, o clima frio levava os elefantes e outros animais exuberantes do interior para a costa. Da mesma forma, os extremamente lascivos semi-nômades do centro do Brasil lançam-se durante o verão em caçadas pelos platôs interiores, mais ou menos como os Aram da Síria, a uns dois mil pés acima do nível do mar. Especialmente em maio, junho e julho, durante o inverno, eles seguem sua caça até as regiões baixas e mais amenas, onde constróem

(14) BURTON, R.F. 1871. On Anthropological Collections from the Holy Land, with notes on the Human Remains by Dr C. Carter-Blake. Journal of the Anthropological Institute, 1: 300-312. Tradução: Francisco Silva Noelli e Lúcio Menezes Ferreira; revisão de Amílcar D’Avila de Mello.

(15) Título original: Notes on the kitchen-middens of São Paulo, Brazil, and the footprints of St. Thomas, alias Zomé. Anthropologia, 1: 44-58. London. 1873. Tradução: Francisco Silva Noelli e Lúcio Menezes Ferreira; revisão de Amílcar D'Avila de Mello. Não incluímos a parte referente às pegadas de São Tomé, devido à sua extensão e por não incluir conteúdos sobre os sambaquis.

(16) Fellow of Royal Geographical Society, Vice-President of the London Anthropological Society.

(17) É um dos livros de Antônio Vieira dos Santos: Memória Histórica, Cronológica, Topográfica e Descritiva da Vila de Paranaguá (1850); Memória Histórica, Cronológica, Topográfica e Descritiva da Vila de Morretes, e do Porto Real ou de Cima (1851). Foram reeditados pelo Museu Paranaense em 1950. 
ranchos nas terras entre os mangues e, enquanto os animais se reproduzem, complementam seus escassos e irregulares alimentos com peixe, ostras e com os músculos que formaram a base da vida de muitas famílias ictiófagas. Cada família ocupa seu próprio monte sobre as margens de algum córrego de água doce e, assim, as ostreiras são, com freqüência, aparentemente duplas. Aqueles que morrem durante o inverno são enterrados, como será visto, entre os restos dos seus banquetes.

A antiguidade desses kjökken-möddings é proporcional ao seu tamanho: os estratos mais baixos também são quase petrificados devido ao longo e contínuo calor e pressão. Os implementos de pedra são toscos ao último grau, servindo apenas para quebrar ou abrir conchas, contrastando fortemente com as belas e bem acabadas armas usadas para lutar. E, também, deve-se considerar que sobre esta parte da costa os "índios", como os Guaianá ${ }^{18}$ (plural, Guaianáses) de Santos e os Carijós da Cananéia foram extintos há quase três séculos. É impossível adivinhar quando os montes foram fundados, então, justifica-se que eu os denomine "pré-históricos".

Ao redor da baía de Santos existem ou existiam aproximadamente vinte desses depósitos. Eles foram noticiados pelo Frei Gaspar como se segue ${ }^{19}$ - "Tanta é a antiguidade destas ostreiras (assim lhe chamam na Capitania de São Paulo, os indios as denominavam sambaqué) que a humidade pelo decurso dos tempos veio a dissolver as conchas de algumas delas, reduzindo-as a uma massa branda, a qual petrificando-se pouco a pouco com calor, formou pedras tão sólidas, que é necessário quebrá-las com marrões ou alavancas, antes de as conduzirem para os fornos onde as resolvem em cal. Destas conchas dos mariscos que comeram os indios, se tem toda a cal desta capitania desde o tempo da fundação até agora, e tarde se acabarão as ostreiras de Santos, São Vicente, Conceição, Iguape, Cananéia, etc. Iguais montinhos se encontram na praia que vai da vila de Laguna às Torres na Provincia de Santa Catarina. Na maior parte delas ainda se conservam inteiras as conchas, e em algumas se acham machados (os dos indios eram de seixo muito rijo), pedaços de panelas quebradas e ossos de defuntos, pois que se algum indio morria no tempo da pescaria, servia de cemitério a ostreira na qual depositavam o cadáver, e depois o cobriam com conchas". Dos sambagués que restam, visitei os mais importantes. Antes de descrevê-los, contudo, também seria possível dar uma breve descrição topográfica da baía muito famosa.

A viagem do Rio de Janeiro, depois de correr ao longo da ilha continental de Santo Amaro, que parece ser parte da costa, projeta-se para o sudoeste, a fortificada Ponta Grossa, diante da Ponta de Monduba, sobre o continente ocidental, e acha-se frente ao que parece ser o estuário ${ }^{20}$ de um poderoso rio, cerca de sete milhas adentro. Avançando poucas milhas vemos que o velho rio de Santo Amaro de Guaimbé, agora Barra de Santos, é uma enseada marinha composta de dois braços. A ocidente está o rio de São Vicente, pitoresco e clássico, mas inútil: sua atual barra é rasa e não comporta a menor embarcação, e tenho motivo para acreditar que ali o nível da terra está subindo. A oriente está o próprio rio Santos, que conduz para a cidade, formando entre ela e o continente um amplo e curvo braço de mar que recebe e conduz para o Atlântico a água doce drenada da alta montanha ao norte.

Fortemente cingida por dois fortes braços está a Ilha de Santos, que os livros chamam de Ilha de São Vicente. Ultimamente tem havido uma disputa acirrada para determinar se este rio ou as águas de Bertioga são o lugar primeiramente visitado, em dois de janeiro de 1532, no dia de São Vicente, por Martim Afonso de Sousa, o explorador e primeiro donatário da costa. Qualquer menção aos argumentos pró ou contra ocuparia muito espaço. De qualquer maneira, o rio ocidental foi sucedido per fas et nefas [por bem ou por mal] pela manutenção do nome. A estreita faixa de areia coberta por baixa vegetação diante do mar é a Praia do Embaré; aqui os santistas

(18) Burton confunde os Guaianá, que eram Jê, com os Tupiniquim, que eram Tupi e autores da toponímia analisada por ele. Os Tupi ocupavam a costa no período histórico mencionado por Burton.

(19) Não cotejamos com a obra original, mantendo estritamente a compilação de Burton.

(20) Burton usou o termo francês embouchure. 
construíram pequenas vilas e cabanas e vêm aos bandos durante o verão para aproveitar o banho no mar raso com grande abundância de peixes. Perto do meio da ilha, formando um vale crescente para o sul está uma excelente referência terrestre, o morro de Monte Serrate, pedreira ferida, vestida de verde, encimada por uma capela branca abandonada e uma útil sinalização auxiliar. Evidentemente, nas eras geológicas esta crista granulosa de rocha gnaisse, de seixos graníticos e argila feldspática foi apenas o pé de um paredão da Serra semicircular continental que o mar lavava, e o resto de ilhas formadas muito depois por seus detritos e pelo movimento das ondas. $\left({ }^{*}\right)$ E como a parte oeste da ilha é elevada, acredito que o leste pode ter abaixado; estas oscilações seculares da terra podem ser verificadas, e cuidadosamente estudadas antes de escavações, tubulações e outras obras públicas.

Agora avançamos para o rio Santos cerca de seis milhas em direção à cidade e voltamos para leste, nordeste e, finalmente, para noroeste. Conforme avançamos, o olhar detém-se sobre um grandioso anfiteatro de montanhas, uma muralha para o ocidente, culminando ao norte e descendo para leste, com os cumes emaranhados de florestas luxuriantes, e geralmente com pesadas nuvens. Isto forma o panorama de fundo da baía. Aqui temos:

A serra altiva, que os cabeços ergue

Calvos, arrepiados, ou cingidos

De donosas palmeiras

Joaquim Norberto.

Está é a Serra do Mar ou da Terra Firme, um prolongamento da cadeia de montanhas orientais brasileiras, cuja secção perto do Rio de Janeiro, a Serra dos Órgãos, é muito admirada. A altitude máxima perto de Santos pode ser de 3.500 pés.

A amplitude do nobre anfiteatro induziu os habitantes Guaianá a chamá-la de Ilha Endoaguassú ou o "grande pilão" (formada por um entroncamento de três vias). Como todas as tribos destas partes, elas deram nomes tão pitorescos quanto musicais; alguns deles são os mais belos e expressivos que se pode imaginar, e temos somente que lamentar quando eles caem em desuso. Hans Stade ${ }^{21}$ (cap. 14), que corrompeu a palavra para Iwawassupe, percorreu justamente o pilão formado pela borda da Serra com as colinas da ilha de Santos. Frei Gaspar, seguido de Varnhagen (vol. 1, p. 141), atribuiu Enguaguaçú ao equivalente português Pilão Grande ou Monjolo; a primeira palavra, contudo, deveria ser Endoa, Endua ou Indoá (em Gonçalves Dias). Varnhagen também está fortemente justificado ao asseverar que o Grande Pilão é derivado de um destes engenhos primitivos que ali havia. ${ }^{22}$ Os modernos, combinando a borda semicircular deste "furo na parede" com a perpétua chuvarada condensada pelos cumes frios das montanhas, comparam a formação com outro artigo de uso doméstico. O símile talvez se harmonize muito melhor, mas é decididamente insosso. Em Hans Stade, também, encontramos o assentamento de São Vicente chamado de Orbioneme, o qual posteriormente os escritores travestiram com Orpiom, e, não tendo medo do francês ante seus olhos, para Morpion. Não sabemos porque ${ }^{23}$ diz Varnhagen: em Purchas, entretanto (v. 1242), achamos Warapisumama e podemos encontrar parte da raiz para Guará, a Íbis,

(*) Nota de Burton: "Em 1857 os seguintes furos foram feitos pelo Sr. Neate, C. E. (Engenheiro Civil), no píer da alfândega de Santos:

Húmus superficial 6 a 16 pés

Bom silte arenoso 14 a 24 pés

Silte argiloso $\quad 16$ a 27 pés

Argila mole $\quad 46$ a 66 pés

Areia grossa 26 a 41 pés"

(21) Burton redigiu Stade, mantendo-o na edição inglesa de 1874 do livro do mercenário alemão.

(22) A parte da frase marcada com itálico foi citada em português por Burton.

(23) Idem. 
muitas das quais foram mortas aqui. Não será necessário descrever aqui a complicação das baías, pontas, ribeirões e braços de mar que dividem a ilha de Santos e a cidade do continente. ${ }^{24}$ Durante nossas visitas aos sambagués aprenderemos o suficiente sobre eles.

Os primeiros kitchen-middens que visitei estão na emaranhada e grandiosa ilha de Santo Amaro, que forma a margem esquerda do rio Santos. Eles estão principalmente nas praias de Bertioga, um braço ribeirinho de mar dividindo a ilha do continente. Os altos montes de berbigões (as conchas venus) próximos da foz ocidental têm sido agora removidos em sua maioria para queima de cal, e os implementos e ossos foram irremediavelmente dispersados. Além disso, outro morne ou morro de terra há muito tem suprido com cal o meu amigo Sr. Porchat. Isto pode ser visto por um rancho ou abrigo coberto de palha. ${ }^{25}$ No limite do lado noroeste as camadas de ostras e venus aparecem misturadas com seixos e húmus marrom, o resto da superfície é coberto por uma densa segunda [camada], e tive dificuldade de medir o tamanho ou a cubagem dos conteúdos do depósito que agora (sete anos depois) provavelmente foram todos removidos. Como de costume, este sambaqui tinha um nome indígena, e as caveiras dos antigos habitantes foram removidas dele para que ele fosse destruído. Considera-se que as pequenas ostras rendem excelente cal. Mais a oeste, na margem setentrional da lagoa do Caeté, encontra-se a ostreira do coronel Candinho Albuquerque, ${ }^{26}$ onde está uma casa de meia-água no centro do canal de Bertioga. Ele escava suas conchas do declive sul de um morro perto da água; os fragmentos cavados com enxada são misturados com terra e amassados junto com água antes de serem transformados em bolas do tamanho de 68 prs., ${ }^{27}$ enxugados no forno, e queimados o quanto desejam. Os montes são notavelmente duplos, planejados para duas famílias. Finalmente, examinei enormes coleções na margem direita do rio de Iriri, ${ }^{28}$ um pequeno regato do lado continental caindo perto do lado leste da foz do Bertioga; conforme meus informantes, eles trabalharam por anos sem diminuição perceptível.

Dois machados "indígenas" enviados à infelizmente defunta Anthropological Society of London, foram descobertos a dois ou três pés abaixo do nível do solo em um morro sobre a Ilha Barnabé. ${ }^{29}$ Esta ilhota é visível de Santos. A cidade cresce para o norte do rio como um porto que é formado por uma superfície coberta por mangue e ribeirões que escoam para a costa. Era conhecida dos velhos como a Ilha dos Padres, porque foi ocupada por missionários jesuítas; agora é chamada assim porque o comendador Barnabé, um poderoso comerciante de Santos, fica ali dois meses do ano. Você desembarca da sua canoa numa massa de seixos coberta de bivalves e outras conchas; daquele ponto uma calçada ou rampa pavimentada conduz até um terraço, a aproximadamente 180 pés acima do nível do mar, sobre o qual está uma casa branca comprida, com cinco janelas e telhado vermelho. $\mathrm{O}$ jardim aparenta um estado selvagem, mas exibe suavidade com as mais delicadas rosas brancas.

Reembarcando, atravessamos um dilatado curso d'água para o norte chamado Lagoa de Santa Rita, um habitual viveiro de patos na estação fria, onde a caça abunda. É o estuário de um pequeno córrego límpido de um contraforte da serra do norte, rolando sobre a areia branca, e muito afetado pelo assoreamento. Escreve-se seu nome "Gerubatuba", "Jeribatyba" e de várias outras maneiras,

(24) Nota de Burton: "Existe uma carta hidrográfica do porto de Santos, do almirante Campbell, da marinha portuguesa. Nenhum plano da cidade foi publicado no meu tempo, mas a câmara municipal tem uma em larga escala, (assinada) C. A. Bressen".

(25) No prefácio ao livro de Hans Staden, Burton (1874: vi) amplia essa informação: "rancho de palha ou cabana para uso dos queimadores de cal".

(26) Tenente Coronel Cândido Anunciado Dias de Albuquerque, realizou nas décadas de 1850 e 1860 diversas obras públicas em Santos.

(27) Unidade cujo significado não atinamos.

(28) Burton grafou como rio Urirí.

(29) Burton grafou como ilha do Bernabé. 
mas significa simplesmente jeri, papagaio, e ubatuba, taquaral. Em outra meia hora passamos a Pedra Redonda (Itapoan), e desembarcamos em Santa Rita, uma velha fazenda dos beneditinos, que tem uma capela num outeiro à esquerda. Originalmente, este lugar da casa de deus foi chamado de Madre de Deus; ele foi construído pelo proprietário do Engenho d'Água, Pero de Góes, primeiro donatário da capitania dos Goitacazes, posteriormente de São Tomé, contendo cinqüenta léguas de costa entre São Vicente e o Espírito Santo. A Madre de Deus posteriormente tornou-se Nossa Senhora das Neves, perpétuo nevoeiro sobre lugar de gelo e neve, que é muito procurado em Santos. Sua bela localização atrai muitos peregrinos em canoas aos domingos e feriados, com bandas e abundante foguetório, e é chique retornar carregando enormes ramos de murtas brasileiras.

Santa Rita agora foi convertida em uma olaria pertencente ao Sr. Francisco de Mendes Neto, e a importância do progresso é demonstrada pelos tijolos estampados "Clayton \& Co’s. Patent". O administrador, Sr. Antônio José da Silva Campello, um inteligente português do Minho e Douro, mostrou-me o estabelecimento e deu-me dois belos machados indígenas. Eles foram encontrados quando cavavam barro para tijolos em um morro argiloso dois ou três pés abaixo da atual superfície do solo. Minha coleção da baía de Santos foi presenteada à Sociedade Antropológica de Londres (por Deus, morta!) e para vários amigos. Para o restante da coleção foi oferecida a quantia de três guinéus cada, e durante minha ausência da Inglaterra, acredito que o Sr. Cutter, naturalista, tornou-se o proprietário de oito.

No domingo, três de dezembro de 1865 , parti em um bote de quatro remos, acompanhado pelo Sr. João Batista da Silva Bueno para visitar os cafezais, fazenda e montes de cal do seu irmão, superintendente da alfândega de Santos. A ilhota cresce para o noroeste do braço de mar de Santos; ela é composta principalmente de argila vermelha, e de longe se mostra elevada como uma sela sobre a praia de mangue, uma casa e jardim na bifurcação ou sede. Remando cerca de cinqüenta minutos chegamos a um tipo de baía, conhecida como Caniư ${ }^{30}$ - "Caneó" em sua forma antiga. E a cerca de uma milha completa, deságua no rio Casqueiro, que, fluindo para sudoeste, completa a insulação de Santos. Passamos por várias canoas fortemente carregadas que desciam apressadamente o rio: o vento ameaçava chuva e soprava do noroeste, e muitas canoas foram alagadas na lagoa. Este é o local exato do meteoro. O ar quente, úmido e leve do "pilão" de Santos encorpa-se e pode ser suprido pelas correntes frias conhecidas como viração (brisa marinha), ou pelas correntes de ar frio das montanhas, com cerca de 3 mil pés acima do nível do mar. Portanto, viajantes indo do platô interior, a 2000 pés de altitude, para a costa não encontram o vento oeste até descerem de 300 a 500 pés na direção da enseada. A ilhota no mangue à esquerda mostra os restos de uma "Casa Forte" ou casa de pedra construída pelos velhos portugueses contra os bugres ("indios"). Em menos de duas horas cobrimos as duas léguas (oito milhas) que separam Santos da ilha do Casqueiro. A fazenda pode ser vista das partes altas da cidade, uma casa entre duas elevações baixas, cercada por vigorosa produção secundária, onde a grama cresceu dentro da própria memória. À direita, marcas pretas aumentam repentinamente no suave declive da face sul: estas são plantações de chá. O morro adjacente é irregularmente coberto com altos pés de café, alho-porró verde e cana-de-açúcar. Na porção sul da "Ilha da Casca", a noroeste do fim da bifurcação do rio marinho de Santos, a uma légua para nordeste, conduzindo para Mogi, está a estação da estrada de ferro Santos-São Paulo, construída no sopé da grande encosta. À esquerda do rio Cubatão, a uma légua e meia de distância, está a ponte da nova ferrovia para a capital. Isto não deve ser confundido com o Cubatão de Mogi, aliás, rio Pissaguera. A palavra foi explicada pelo Frei Gaspar (p. 68): "portos a que chamam cubatões". Aqui Martim Afonso de Souza desembarcou para explorar o interior e o primeiro nome do lugar foi Porto das Almadias ${ }^{31}$ (das canoas). Ele foi posteri- 
ormente dos jesuítas do colégio de Santos, e recebeu o nome de Porto de Santa Cruz.

Desembarcamos no sul da ilha dentro de uma nuvem de mosquitos e sandflies ${ }^{32}$ que atacaram especialmente no abrigo da cabine. Aqui também há uma fábrica de cal suprida por um sambagué vizinho, o primeiro de três. Ainda há restos de ostras, mas a maior parte do depósito foi queimada. Inspecionamos cuidadosamente a grande plantação de chá, vimos a colheita das folhas e a torrefação em uma assadeira de ferro, e bebemos a infusão feita ali mesmo. Ela tem um interessante gosto de perfume e perguntei se alguma erva fora misturada. $\mathrm{O}$ anfitrião respondeu que não. Alguma, contudo, foi usada com esse objetivo, como uma pequena flor branca (Flor do Imperador?), e adulteram com outras folhas de chá de uma planta indígena chamada Jubão. Eles descreveram-no carregando uma pequena flor azul com cinco pétalas (??). O chá é considerado um cultivo indígena no Brasil, e Labat nos disse que ele cresce selvagem nas Antilhas. $\mathrm{O}$ assunto é muito extenso para ser tratado neste artigo, mas o mundo não ouviu falar ou não provou este chá brasileiro.

Depois de um farto café da manhã partimos para a parte noroeste da Ilha do Casqueiro, guiados pelos passos mais lentos do septuagenário Senhor João. Aqui estão as ruínas de um velho forno de cal que, durante muitos anos antes do nascimento do nosso guia, foi abastecido pela ostreira ao lado. O monte começa na praia do mangue, e gradualmente eleva-se até uma altura próxima aos 200 pés; o comprimento e a largura tinham aproximadamente 2800 pés. Então, é fácil calcular a cubagem. A decadência dos anos revestiu a superfície irregular com uma camada de húmus marrom e, aqui e ali, árvores altas cresceram na grossa capoeira.

Uma parte do monte apresenta ostras e outras conchas dispersas em camadas separadas por terra; não há uma regularidade, os restos do mar aparentemente foram lançados ao acaso - de fato, jogados fora após o uso. Nos locais de calor e mistura super abundantes formaram-se blocos conglomerados compactos que pesavam meia tonelada, como nos mostraram. Eles continham restos de siris e camarões, enquanto ossos longos de peixe e espinhas apareceram dispersas entre as conchas. Foi dito que vários esqueletos foram apanhados nesse monte e nosso guia tinha uma teoria de que os nativos queimaram seus mortos nos montes de ostras, mas nunca entre os berbigões (bivalves, principalmente as venus). Achamos apenas um fragmento de esqueleto, ${ }^{33}$ que apresentava um tamanho que dificilmente valeria uma ida ao n. 4 da St. Martin's Place. ${ }^{34} \mathrm{Um}$ machado quebrado de pedra preta foi extraído com picareta. Nosso guia encontrou um seixo que estava no chão, evidentemente com o propósito de abrir moluscos. Ele também me disse que o chamava Pedra Taúna (de ita una, a última sílaba contraída de pituna, significando preto, e não como pensamos então, pedra de moer, do árabe Táhún, uma mó), porosa, preta, cuidadosamente arredondada, ${ }^{35}$ e apanhada, se supõe, no rio Mogi ou na Cachoeira de Cubatão. Muitas dessas pedras, pesando meia libra, em número de nove a quatorze, são sempre encontradas depositadas na cabeça ou nos pés dos esqueletos. Evidentemente, eles são instrumentos de trabalho doméstico, provavelmente para quebrar grãos, colocado para uso da alma. É pouco provável que os Tupi tivessem almas ou espíritos.

Então cruzamos um rio raso até um monte similar, mas não tão grande. Nosso anfitrião acredita que as famílias tinham seus locais para acampar, onde construíam suas enormes Tabas, ou seus abrigos de postes e esteiras que compunham suas aldeias. Isto não é improvável.

Então voltamos em direção ao nordeste da ilha e encontramos outro depósito de conchas de dimensões semelhantes ao que vimos acima. Como é comum, estavam cobertos de capoeira e

(31) Burton grafou "armadias".

(32) Mosquito-palha, Gen. Lutzomyia.

(33) Burton escreveu calvaria.

(34) Provavelmente um antiquário da St. Martin Lane, em Londres.

(35) Nota de Burton: "aparentemente com algum trabalho na água". 
erodidos pelas chuvas torrenciais, com pequenas valas; não eram fáceis de escalar. Escavamos com picareta alguns ossos humanos e as pedras arredondadas mencionadas acima, mas não conseguimos achar um crânio completo. Esse monte também é duplo, dividido por um riacho, e, na ilha, no mangue do outro lado do rio Mugi, havia uma elevação pontuda semelhante.

A respeito dos sambaqués, o Senhor João comentou que na chegada dos portugueses eles foram encontrados já feitos, mostrando o trabalho de muitos séculos. Além disso, eles sugerem que as tribos nativas devem ter sido muito mais numerosas do que geralmente se supunha. Além das evidências dos montes de conchas (às quais dou pouca importância), ele observou que toda a região ao redor da baía de Santos era completamente deficiente em verdadeira e antiga "Mata Virgem", o que prova que ela foi desmatada uma vez. O ignorante não consegue acreditar que esses montes resultaram de trabalho manual do homem, atribuindo-o ao dilúvio de Noé, ou a algum outro suposto distúrbio. Homens instruídos têm igualmente defendido esse absurdo em publicações. 